\title{
OPEN Soil-applied selenite increases selenium and reduces cadmium in roots of Moringa oleifera
}

\author{
Zhiqiu Fu ${ }^{1}$, Gang Liu ${ }^{1 凶}$, Lijuan Du ${ }^{2 凶}$, Luxiang Wang ${ }^{2}$, Hongmei Yan ${ }^{2}$, Benlin Yin ${ }^{2} \&$ \\ Quanhong $\mathrm{Ou}^{1}$
}

Deficiency of selenium (Se) will lead to malnutrition and decreased immune function of the body. There is a common phenomenon of Se deficiency in foods. In this study, different concentrations of sodium selenite $\left(\mathrm{Na}_{2} \mathrm{SeO}_{3}\right)$ were applied to Moringa oleifera grownin soil. The purpose was to explore the feasibility of Se biofortification of $M$. oleifera root. The effect of exogenous Se on the accumulation of Se and cadmium (Cd) in the roots of $M$. oleifera was studied by inductively coupled plasma mass spectrometry, and the mechanism of exogenous $\mathrm{Se}$ on the accumulation of $\mathrm{Se}$ and $\mathrm{Cd}$ in the roots was studied by Fourier transform infrared spectroscopy (FTIR) combined with principal component analysis and partial least squares regression analysis. The results showed that $\mathrm{Na}_{2} \mathrm{SeO}_{3}$ significantly affected the accumulation of $\mathrm{Se}$ and $\mathrm{Cd}$ in the roots $(p<0.05)$. The increase in Se was highest when $\mathrm{Na}_{2} \mathrm{SeO}_{3}$ was around $4.0 \mathrm{mg} / \mathrm{kg}$, which increased by $315 \%$ compared with the control. The decrease in Cd was the lowest when $\mathrm{Na}_{2} \mathrm{SeO}_{3}$ was around $2.0 \mathrm{mg} / \mathrm{kg}$, which decreased by $80 \%$ compared with the control. The results of FTIR analysis showed that $\mathrm{Na}_{2} \mathrm{SeO}_{3}$ treatment changed the carboxylate, phosphate radical, hemicellulose and protein in roots of $M$. oleifera, while the increase of Se was related to hemicellulose, protein, polysaccharide and lignin, and the decrease of $\mathrm{Cd}$ was related to hemicellulose and protein. The results showed that exogenous Se increased the accumulation of Se and inhibited the absorption of Cd. Therefore, the roots of $M$. oleifera can be used in Se biofortified products.

$\mathrm{Cd}$ is a toxic element, and the long-term exposure of human body to $\mathrm{Cd}$ will lead to many diseases, such as renal insufficiency, osteoporosis and even cancer ${ }^{1}$. For the average non-smoking population, about $90 \%$ of Cd exposure generally comes from food consumption ${ }^{2}$. The movement of $\mathrm{Cd}$ from soil to plant system is strong, so it is easy to be absorbed by crops and enter the food chain, which can affect the yield and quality of crops. Therefore, reducing the absorption of $\mathrm{Cd}$ by crops is the key to control human exposure to $\mathrm{Cd}$. The accumulation of Cd in plants will interfere with normal cell function and metabolism, resulting in a series of adverse reactions, such as growth retardation, inhibition of photosynthesis, inhibition of the synthesis of some enzymes, formation of free radicals and changes in ultrastructure at all levels ${ }^{3-5}$. A large amount of active oxygen generated by Cd through enzymatic and non-enzymatic reactions can cause non-specific oxidation of proteins and membrane lipids or DNA damage ${ }^{6,7}$.

Se is an essential trace element for human body. It plays an important role in the biological processes such as antioxidant response, thyroid hormone production, immune response, which can improve cardiovascular disease, muscle disorder and immunity decline ${ }^{8}$. Se is also involved in the synthesis of glutathione peroxidase and thioredoxin reductase ${ }^{9}$. The human body absorbs Se mainly through food. It is an effective way to supplement Se is by eating Se-rich food. Adding a suitable amount of Se can promote the growth of plants, improve the quality of crops, enhance the stress resistance of crops, and improve the yield and Se content of crops ${ }^{10}$. In addition, appropriate application amount of Se can also improve the osmotic regulation ability of plants and reduce the toxic effects of heavy metals ${ }^{11}$.

Moringa oleifera is an edible medicinal plant, which is widely grown in Southeast Asia and Africa, and has attracted much attention as a "natural nutrition in tropical regions". All parts of M. oleifera have medicinal and nutritional functions. Its pods and leaves are rich in protein, amino acids, unsaturated fatty acids, bioactive substances and essential minerals ${ }^{11-13}$. The tender leaves and young pods can be used as vegetables, and leaf powder can also be added to flour to make M. oleifera noodles. Glucosinolates extracted from M. oleifera leaves have

${ }^{1}$ School of Physics and Electronic Information, Yunnan Normal University, Kunming 650500, China. ${ }^{2}$ Institute of Quality Standards and Testing Technology, Yunnan Academy of Agricultural Sciences, Kunming 650223, China. ${ }^{\varpi}$ email: gliu66@163.com; 43489106@qq.com 

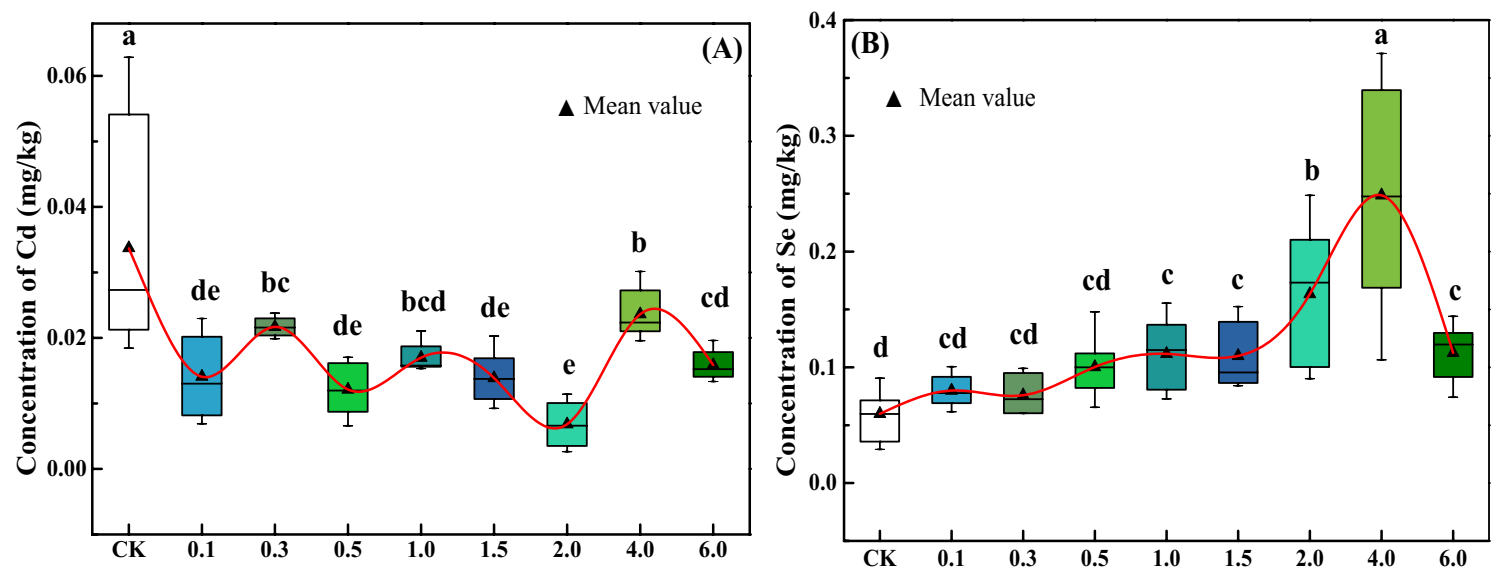

Figure 1. Box plots of $\mathrm{Cd}(\mathbf{A})$ and $\mathrm{Se}(\mathbf{B})$ concentrations in roots of M. oleifera. Boxes with different lowercase letters indicate significant differences in the mean between different treatments $(p<0.05)$.

anticancer properties ${ }^{14,15}$, and flavonoids and polyphenols from the leaves have hypoglycemic, hypolipidemic and antioxidant effects ${ }^{16}$. Oreochromis niloticus (Nile tilapia fish) can effectively improve chlorpyrifos induced growth retardation, immune suppression, oxidative stress and DNA damage by eating M. oleifera leaves ${ }^{17} . M$. oleifera seeds are rich in unsaturated fatty acids and low molecular water-soluble proteins. The low molecular water-soluble proteins from $M$. oleifera seeds can be used as biological water purification agents ${ }^{18,19}$. M. oleifera flowers are a good source of ethyl carbamate and flavone and other substances, which have useful antimicrobial, anti-inflammation and anti-diabetes effects ${ }^{20,21}$. The agents-1,3-dibenzylurea and aurantiamide acetate extracted from $M$. oleifera root have anti-inflammatory and analgesic effects ${ }^{22}$, and the polysaccharide in the roots also has anti-inflammatory and antibacterial effects ${ }^{23}$. Therefore, $M$. oleifera roots can be used to treat low back pain, gout, rheumatism and lithiasis and other diseases ${ }^{24}$.

Plant roots are the main organ to absorb nutrients, and also the main place to synthesize amino acids, organic acids and various hormones in plants. Roots can also transport and distribute assimilates, so roots have a close relationship with the growth and development of other organs of plants. Root is the channel for nutrients and minerals to enter the plant, which will lead to elements such as Se and Cd to enter the food chain. In this study, we hypothesize that selenium could be enriched to reduce the $\mathrm{Cd}$ concentration in plants, and the current research wants to find a more effective method to reduce the $\mathrm{Cd}$ concentration of $M$. oleifera root. Thus, $M$. oleifera was cultivated with different concentrations of $\mathrm{Na}_{2} \mathrm{SeO}_{3}$ in soil to assess the effect of $\mathrm{Se}$ and $\mathrm{Cd}$ accumulation in the roots affected by exogenous Se.

\section{Results}

$\mathrm{Cd}$ and Se accumulation in $\mathbf{M}$. oleifera roots. ICP-MS results (Fig. 1) showed that the application of all concentration of $\mathrm{Na}_{2} \mathrm{SeO}_{3}$ significantly reduced the concentration of $\mathrm{Cd}(p<0.05)$ whereas significantly enhanced concentration of Se in roots of $M$. oleifera $(p<0.05)$ than control sample. When $\mathrm{Na}_{2} \mathrm{SeO}_{3}$ was added to the soil less than $4.0 \mathrm{mg} / \mathrm{kg}$, the concentration of Se accumulation in the root increased with the increase of the added amount. The concentration of Se decreases significantly $(p<0.05)$ while added above $4.0 \mathrm{mg} / \mathrm{kg}$. Compared with the control group, Se increased $27-315 \%$ and Cd decreased $30-80 \%$ in the roots of $M$. oleifera with treatment of $\mathrm{Na}_{2} \mathrm{SeO}_{3}$ in soil.

FTIR spectroscopy analysis. FTIR spectra of $M$. oleifera roots are shown in Fig. 2. O-H or N-H stretching vibration was at $3390 \mathrm{~cm}^{-1}$. The peaks around 2927 and $2884 \mathrm{~cm}^{-1}$ were assigned to methyl and methylene stretching vibrations ${ }^{25}$. The absorption peak of the vibration of the saturated ester groups compounds appeared around $1740 \mathrm{~cm}^{-126}$ and the peak at $1643 \mathrm{~cm}^{-1}$ which was ascribed to the $\mathrm{C}=\mathrm{O}$ stretching vibrations of carboxylic anions, hemicelluloses or amide groups in proteins ${ }^{27}$. The peak around $1517 \mathrm{~cm}^{-1}$ was attributed to lignin ${ }^{28}$. Carboxylate vibration was at $1421 \mathrm{~cm}^{-129}$. The peaks around 1241 and $859 \mathrm{~cm}^{-1}$ were due to the S-O stretching vibrations $\mathrm{s}^{30}$. The peaks at 1160,1079 and $1020 \mathrm{~cm}^{-1}$ suggested the presence of hemicelluloses ${ }^{28}$. The peak around $929 \mathrm{~cm}^{-1}$ was ascribed to the vibration of $\beta$-glycoside $\mathrm{e}^{23}$ and the peak at $765 \mathrm{~cm}^{-1}$ due to the vibration of $\alpha$-glycoside ${ }^{31}$. The peak of S-O in the control sample was at $1238 \mathrm{~cm}^{-1}$. After the addition of exogenous Se, the peaks hifted to $1242 \mathrm{~cm}^{-1}$. Therefore, the addition of exogenous Se may affect $\mathrm{S}$ in roots of M. oleifera.

PCA of spectra. PCA was used to reduce the dimensionality of the spectral data to understand the possible sources of the explained differences. From the PCA score plot (Fig. 3a), it can be seen that the FTIR spectra of M. oleifera root cultivated under different conditions could be accurately separated.

The loadings plot was examined to establish possible sources of variance within the spectra, and several areas of high variance were identified. Therefore, the loading plot of PCA can be used to explain the changes in the composition of $M$. oleifera roots cultivated under different conditions. According to $\mathrm{PC}_{1}$ loadings plot (Fig. 3b), there are strong positive weighted peaks around 3604,3120 and $2884 \mathrm{~cm}^{-1}$, which are related to the stretching vibration of carboxyl and methyl groups. A positively weighted peak at $1681 \mathrm{~cm}^{-1}$, was due to hemicelluloses and 


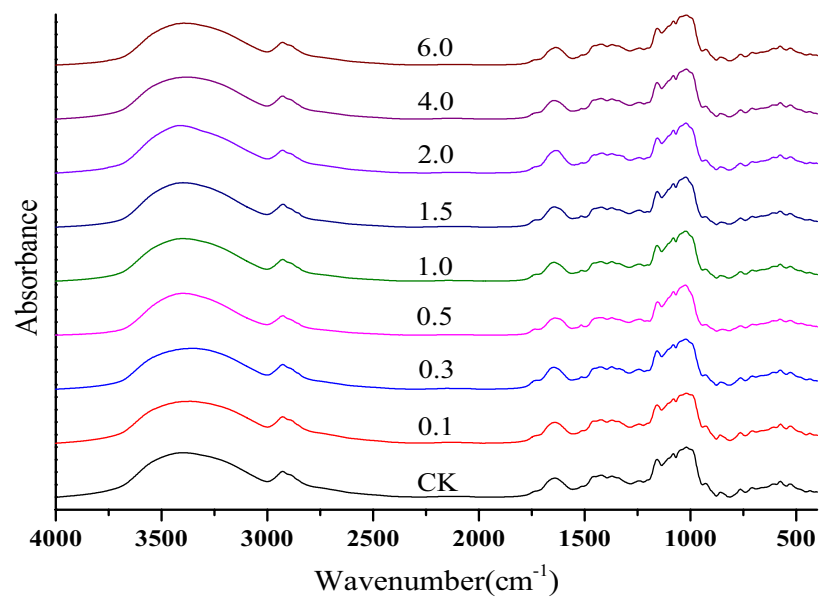

Figure 2. FTIR spectra of cultivated $M$. oleifera roots with $\mathrm{Na}_{2} \mathrm{SeO}_{3}$ concentration of $0,0.1,0.3,0.5,1.0,1.5,2.0$, 4.0 and $6.0 \mathrm{mg} / \mathrm{kg}$.
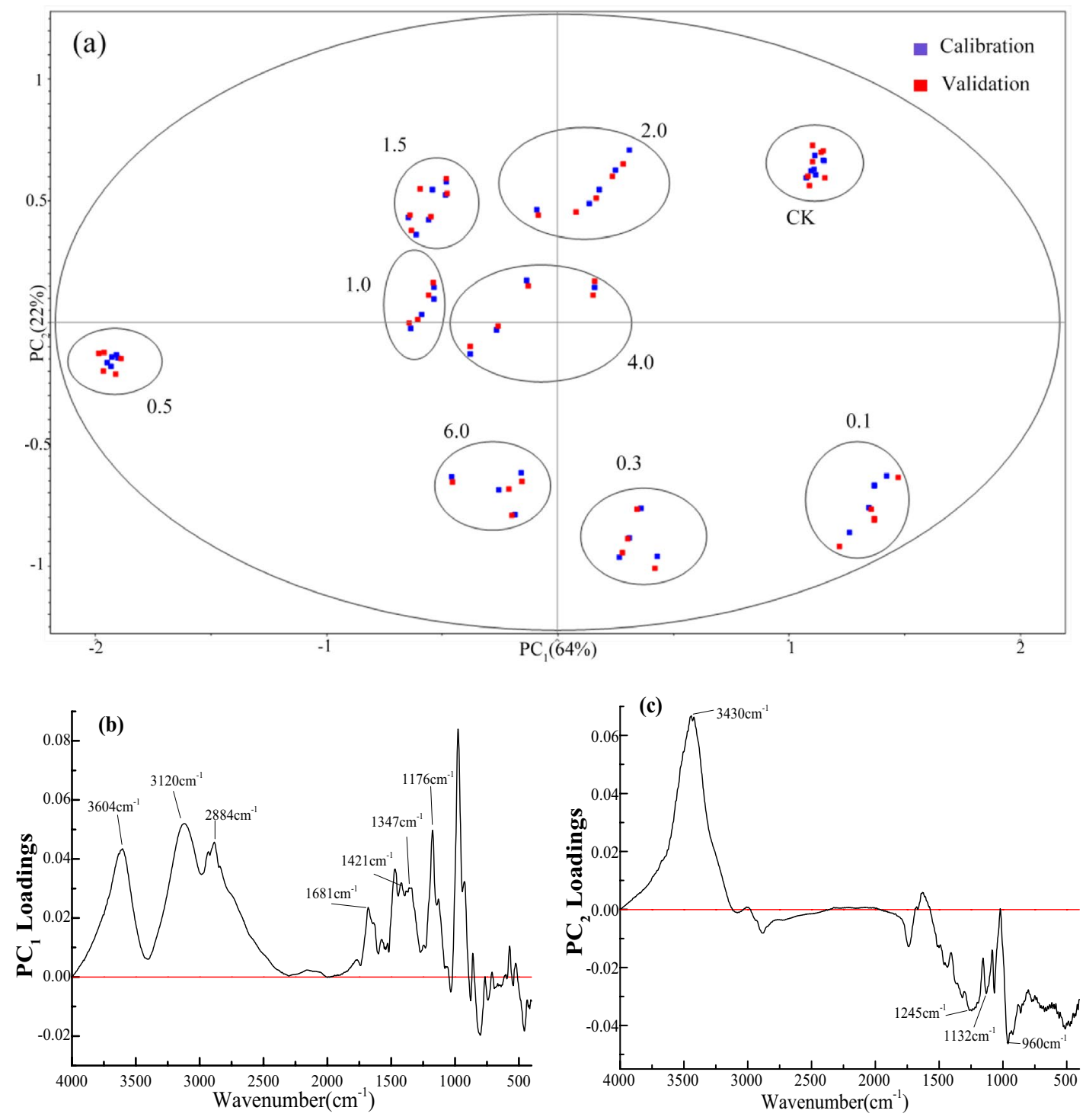

Figure 3. PCA scores plot of FTIR spectra of $M$. oleifera roots cultivated at different concentrations of $\mathrm{Na}_{2} \mathrm{SeO}_{3}$ : (a) PCA scores plot; (b) $\mathrm{PC}_{1}$ loadings plot; (c) $\mathrm{PC}_{2}$ loadings plot. 

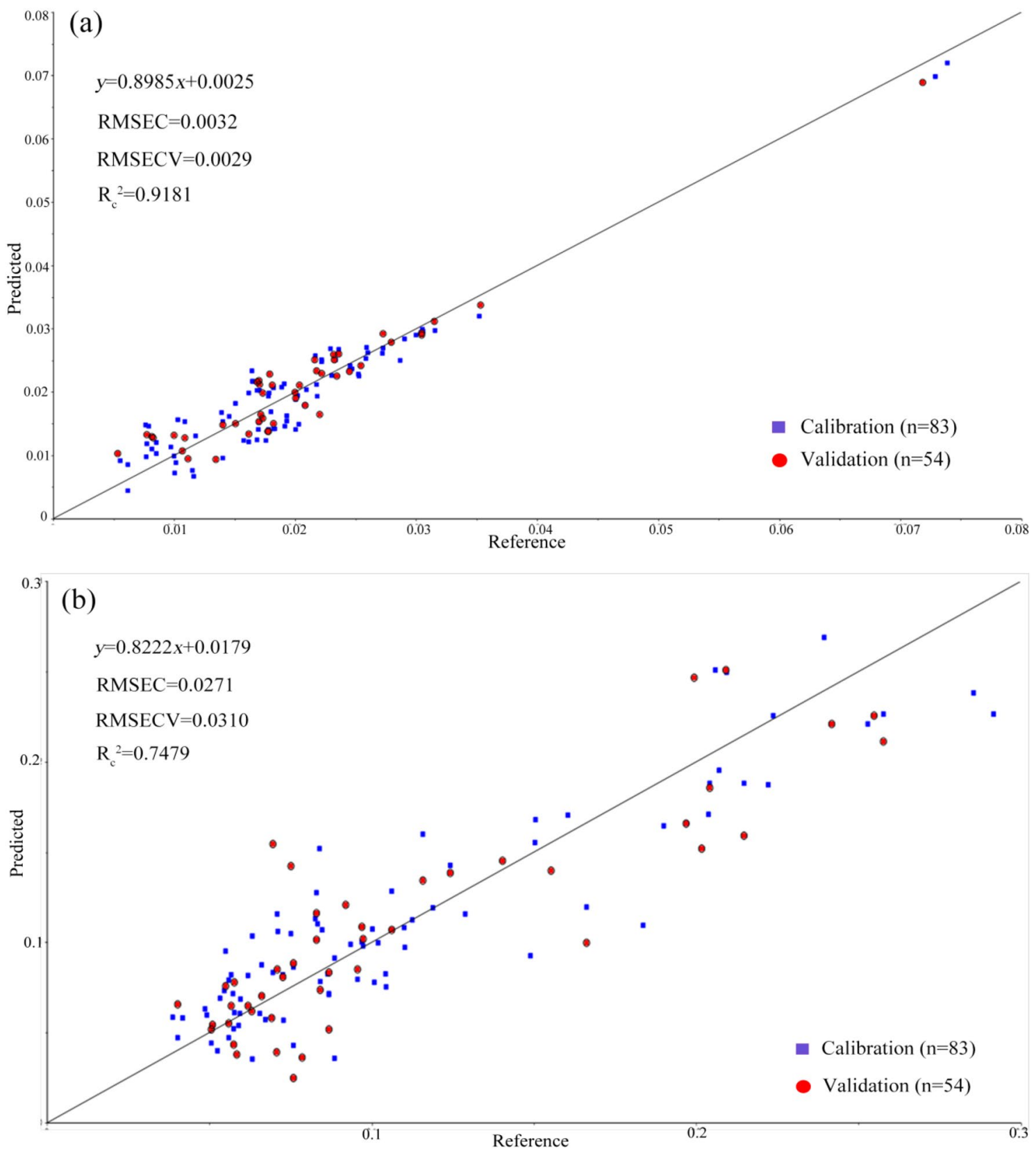

Figure 4. PLSR prediction model for Cd (a) and Se (b). "RMSEC":root mean square error of calibration; "RMSECV":root mean square error of cross validation.

amide $^{27}$. The positively weighted peaks around 1421 and $1347 \mathrm{~cm}^{-1}$ were related to carboxylate radical ${ }^{29}$, and the positively weighted peak at $1176 \mathrm{~cm}^{-1}$ due to hemicelluloses ${ }^{28}$. Therefore, the loadings plot of $\mathrm{PC}_{1}$ is related to the changes of carboxylate and hemicellulose in the roots, and proteins may also be involved. The load of $\mathrm{PC}_{2}$ Fig. $3 \mathrm{c}$ has a strong positive weighted peak around $3430 \mathrm{~cm}^{-1}$, which is related to $\mathrm{O}-\mathrm{H}$ or $\mathrm{N}-\mathrm{H}$ stretching vibration. The negatively weighted peak at $1245 \mathrm{~cm}^{-1}$, was due to amide III, and the negative weighted peaks around 1132 and $960 \mathrm{~cm}^{-1}$ were related to the $\mathrm{PO}_{4}{ }^{3-}$ stretching vibration ${ }^{31,32}$. Therefore, the loadings plot of $\mathrm{PC}_{2}$ is related to the changes of $\mathrm{PO}_{4}{ }^{3-}$ and proteins in roots of $M$. oleifera. The results of PCA showed that the main sources of FTIR difference in $M$. oleifera roots were carboxylate, $\mathrm{PO}_{4}{ }^{3-}$, hemicellulose and proteins.

PLSR analysis. In order to understand the effect of related components in the root of M. oleifera on the accumulation of Cd and Se, the PLSR analysis of Cd and Se was established by infrared spectra $\left(4000 \sim 400 \mathrm{~cm}^{-1}\right)$, as shown in Fig. 4. The determination coefficients $\left(\mathrm{R}_{\mathrm{c}}^{2}\right)$ for the PLSR analysis of Cd and Se were 0.9181 and 0.7479 respectively. Figure 5a shows the loadings plot of the wavenumber weight in the PLSR analysis of Cd. There are positive weighted peak around $1660 \mathrm{~cm}^{-1}$ and negative weighted peak around $1616 \mathrm{~cm}^{-1}$, the two peaks are related to amide I in the protein. The positive weighted peak around $1542 \mathrm{~cm}^{-1}$ is related to amide II. There are positive weighted peaks around 1176, 1108 and $1062 \mathrm{~cm}^{-1}$ which are related to hemicellulose. Therefore, the 

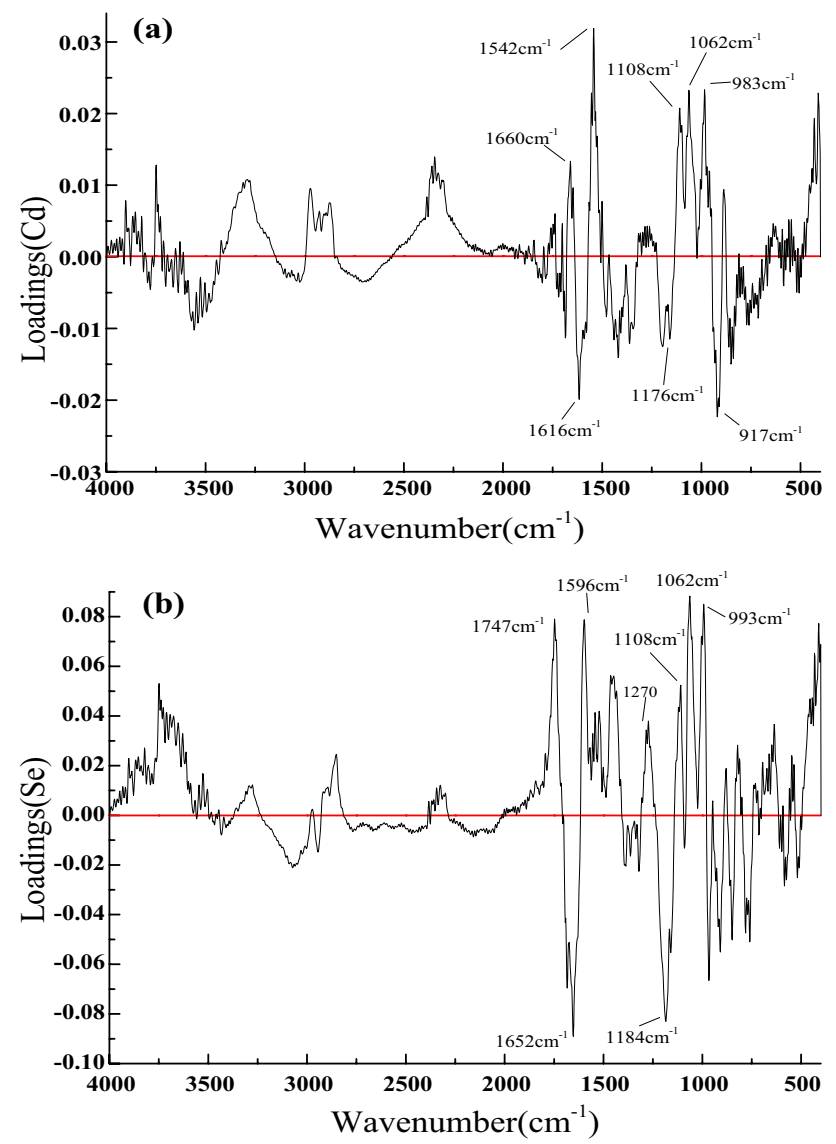

Figure 5. Loadings plot PLSR prediction model for Cd (a) and Se (b).

content of Cd in roots of $M$. oleifera might be affected by protein and hemicellulose. Figure $5 \mathrm{~b}$ shows the loadings plot of the wavenumber weight in the PLSR analysis of Se. The positive weighted peak around $1747 \mathrm{~cm}^{-1}$ was related to hemicelluloses. The negative weighted peak at $1652 \mathrm{~cm}^{-1}$, indicative of carbonyl groups, hemicelluloses and amide, and the positive weighted peak around $1596 \mathrm{~cm}^{-1}$ is related to amide II of protein. The positive weighted peak around $1270 \mathrm{~cm}^{-1}$ is related to guaiacyl ringin in lignin ${ }^{33}$. The positive weighted peaks around 1108 and $1062 \mathrm{~cm}^{-1}$ and the negative weighted peaks around $1184 \mathrm{~cm}^{-1}$ are related to hemicellulose, while the positive weighted peaks around $993 \mathrm{~cm}^{-1}$ are related to polysaccharide vibration. Therefore, the content of Se in roots of $M$. oleifera might be affected by protein, hemicellulose, lignin and polysaccharide.

\section{Discussion}

In this study, the cultivation of $M$. oleifera root by adding $\mathrm{Na}_{2} \mathrm{SeO}_{3}$ significantly increased the Se concentration. Previous studies have shown that Moringa has the exceptional ability to extract Se from the soil and accumulate it in the leaves, which is significantly higher than other plants ${ }^{34,35}$, and it probably also applies to roots. Plants absorb Se from the environment mainly via the roots. Selenite absorbed into the roots will be transported to various parts of the plant, but the selenite retained in the roots was higher than those transported to other parts, so the Se content in the roots was generally higher ${ }^{36}$.

Plant plasma membrane can maintain normal intracellular homeostasis and nutrition, and participate in the perception and response to various environmental stimuli, while the protein of plant plasma membrane plays an important role in response to the external environment. The results of FTIR and PCA showed that when different concentrations of $\mathrm{Na}_{2} \mathrm{SeO}_{3}$ were used to cultivate $M$. oleifera, the $\mathrm{PO}_{4}{ }^{3-}$ and protein in roots of $M$. oleifera were changed. This is due to the perception of plant roots to the external environment, mainly by reversible phosphorylation of the sensing protein, and using the membrane related G-protein, polyphosphoinositide signal pathway and other signal pathways for transmission ${ }^{37}$. Some studies have also found that the active absorption of Se is regulated by phosphate transporters ${ }^{38}$. Se can bind to sulfhydryl groups in certain proteins and inhibit Cd from entering cells ${ }^{39}$. Therefore, adding different concentrations of exogenous Se can change the growth environment of roots of $M$. oleifera. By regulating the abundance of proteins related tochannels, transporters and membrane vesicles transport, the root cells can promote or inhibit the absorption and transport of substances.

The absorption and accumulation of elements in plants are influenced by external environment (such as $\mathrm{pH}$, humidity and temperature of soil), the regulation of transcription factors and the expression of related genes. bHLH transcription factors and jasmonic which are widely found in plants, play an important role in plant growth and secondary metabolite synthesis ${ }^{40}$. The bHLH transcription factors can increase the tolerance of 


\begin{tabular}{|l|l|l|l|}
\hline Properties & Amount & Properties & Amount $(\mathbf{m g} / \mathrm{kg})$ \\
\hline Soil organic matter & $4.34 \%$ & $\mathrm{Mg}$ & 2602 \\
\hline $\mathrm{pH}$ & 5.9 & $\mathrm{Na}$ & 371.7 \\
\hline $\mathrm{Al}$ & $58,770 \mathrm{mg} / \mathrm{kg}$ & $\mathrm{P}$ & 406.2 \\
\hline $\mathrm{Cd}$ & $1.171 \mathrm{mg} / \mathrm{kg}$ & $\mathrm{Se}$ & 1.90 \\
\hline $\mathrm{Fe}$ & $29,500 \mathrm{mg} / \mathrm{kg}$ & $\mathrm{Si}$ & 6.15 \\
\hline $\mathrm{K}$ & $7616 \mathrm{mg} / \mathrm{kg}$ & $\mathrm{Zn}$ & 184 \\
\hline
\end{tabular}

Table 1. Chemical characterization of red soil. The detected elements were total.

Arabidopsis to $\mathrm{Zn}$ and $\mathrm{Ni}^{41}$, and also affect the response of plants to $\mathrm{Cd}$ absorption ${ }^{42}$. Jasmonic can improve the activity of stress resistant enzyme, and then promote the synthesis of alkaloids, flavonoids and antioxidants ${ }^{40}$. Previous studies have found that exogenous Se can up regulate the gene expression of hormone synthetase in plants, promote the synthesis of hormones such as jasmonate or methyl jasmonate, thereby inducing plants to absorb Se externally and increase the amount of $\mathrm{Se}^{43} \cdot \mathrm{Na}_{2} \mathrm{SeO}_{3}$ enabled strawberry plants to improve the activity of antioxidant enzyme glutathione reductase and the activity of L-galactono-1, 4-lactone dehydrogenase responsible for the biosynthesis of ascorbate, to fight against cadmium stress ${ }^{10}$.

When $\mathrm{Na}_{2} \mathrm{SeO}_{3}$ was added to $M$. oleifera, the carboxyl group, hemicellulose and lignin in Moringa root changed, and the concentration of $\mathrm{Cd}$ in the root was significantly reduced $(p<0.05)$. According to the analysis of PLSR, the concentration of Cd was related to hemicellulose, which was consistent with the results of Guo et al. ${ }^{28}$. Root Cd mainly exists in the polysaccharides of the cell wall, which is attributed to the binding effect of the carboxyl and carboxylate groups in hemicellulose on Cd ions ${ }^{44}$. Therefore, exogenous Se caused the changes of hemicellulose and protein in the roots of M. oleifera, and effectively reduce the absorption of $\mathrm{Cd}$. It has been reported that exogenous $\mathrm{Na}_{2} \mathrm{SeO}_{3}$ changes the number of cells per unit area of xylem in the root ${ }^{45}$, and increases the content of pectin and hemicellulose in the cell wall of the root ${ }^{46}$, the results of these studies were consistent with the results of our study. Exogenous Se changed the polysaccharides in roots, and affected the concentration of $\mathrm{Cd}$ in the roots.

\section{Materials and methods}

Cultivation of $\boldsymbol{M}$. oleifera and experimental design. M. oleifera cultivation experiments were conducted from March 2017 to July 2018 in Xishuangbanna, Yunnan, China $\left(101^{\circ} 25^{\prime} \mathrm{N}, 21^{\circ} 41^{\prime} \mathrm{E}\right)$. The soil for cultivation was taken from the acidic red soil locally in Xishuangbanna and collected from the 0 to $20 \mathrm{~cm}$ soil layer. The plant residue were removed from the soil and passed through a 10 mesh sieve after air-drying. Each pot used for cultivation was filled with $5 \mathrm{~kg}$ of soil. The basic properties of soil were shown in Table 1.

M. oleifera seed was obtained from Yunnan Manze Biotechnology Co., Ltd., Chian. Since selenite tends to accumulate more selenium in the roots of plants, this study applied selenite to cultivate $M$. oleifera. Eight experimental groups with $\mathrm{Na}_{2} \mathrm{SeO}_{3}$ and one blank control group were set up, the concentrations of $\mathrm{Na}_{2} \mathrm{SeO}_{3}$ in soil were $0,0.1,0.3,0.5,1.0,1.5,2.0,4.0$ and $6.0 \mathrm{mg} / \mathrm{kg}$, respectively. Each treatment had three parallel experiments, 27 pots in total. Two seeds were planted in each pot and growing under natural light and temperature conditions. After 16 months, the plants were harvested and divided into leaves, stems and roots. The roots were washed with tap water and deionized water and dried to constant weight in a drying oven $\left(50^{\circ} \mathrm{C}\right)$, and then digested and analyzed.

Measurement of total Se and Cd in dry matter. Three parallel experiments were carried out for each M. oleifera, and three blank groups of samples were set. $10 \mathrm{~mL} 69 \% \mathrm{HNO}_{3}$ and $1 \mathrm{~mL} 70 \% \mathrm{HClO}_{4}$ were used for digestion of samples $(0.50 \mathrm{~g})$. For digestion, a high-performance graphite furnace digestion system (DigiBlock ED54-iTouch, China) equipped with advanced composite PTFE vessels was used. The decomposition of organic matter was carried out at atmospheric pressure. When the rest digested solutions were clear with a volume of about $3 \mathrm{~mL}, 1 \mathrm{ml}$ of $2 \% \mathrm{HNO}_{3}$ and deionized water was used to adjust the samples to constant volume (25 mL). The total Cd and Se concentration was measured by ICP-MS (Elan DRC-e, Perkin Elmer, USA). In order to validate the methods, the standard reference materials soybean (GBW10013, China) were used as reference materials to assess the experimental procedures. The standard values of $\mathrm{Cd}$ and $\mathrm{Se}$ in reference materials were 0.011 and $0.022 \mathrm{mg} / \mathrm{kg}$, respectively. The Cd and Se values of the reference materials measured by ICP-MS were $0.012 \pm 0.003$ and $0.024 \pm 0.004 \mathrm{mg} / \mathrm{kg}(\mathrm{n}=3)$, respectively. Therefore, recoveries of Cd and Se in samples ranged from 92 to $109 \%$ and $95 \sim 112 \%$ respectively.

Detection and analysis methods of FTIR spectroscopy. Infrared spectra were acquired using FTIR Spectroscopy (Frontier, Perkin Elmer, USA) equipped with a DTGS detector. All spectra were recorded in the range of $4000-400 \mathrm{~cm}^{-1}$ with a $4 \mathrm{~cm}^{-1}$ resolution and 16 scans. All samples were measured by $\mathrm{KBr}$ pellet method. The interferences of $\mathrm{H}_{2} \mathrm{O}$ and $\mathrm{CO}_{2}$ as well as $\mathrm{KBr}$ background were subtracted automatically when scanning. Quadruplicate spectra were collected for each sample. The average spectra were used for PCA and PLS regression analysis performed by using The Unscrambler X 10.4 software. 


\section{Conclusion}

In conclusion, exogenous Se significantly increased the content of Se in roots of M. oleifera, while significantly reduced the content of $\mathrm{Cd}$. As our present study was only utilized the roots of $M$. oleifera, the effects of exogenous Se on the leaves of $M$. oleifera may be different. Therefore, it is necessary to further study the effect of exogenous Se on Cd and Se accumulation in M. oleifera. Even so, the results of this study still provide information for the roots of $M$. oleifera as a Se-enriched product.

Received: 17 June 2020; Accepted: 29 October 2020

Published online: 23 November 2020

\section{References}

1. Åkesson, A. et al. Non-renal effects and the risk assessment of environmental cadmium exposure. Environ. Health Perspect. 122, 431-438 (2014).

2. Clemens, S., Aarts, M. G. M., Thomine, S. \& Verbruggen, N. Plant science: the key to preventing slow cadmium poisoning. Trends Plant Sci. 18, 92-99 (2013).

3. Cherif, J. et al. Spectroscopic studies of photosynthetic responses of tomato plants to the interaction of zinc and cadmium toxicity. J. Photochem. Photobiol. B 111, 9-16 (2012).

4. Susana, M. G. et al. Unravelling cadmium toxicity and tolerance in plants: Insight into regulatory mechanisms. Environ. Exp. Bot. 83, 33-46 (2012).

5. Marta, M., Davide, I., Elena, M. \& Nelson, M. The response of Populus spp. to cadmium stress: chemical, morphological and proteomics study. Chemosphere 93, 1333-1344 (2013).

6. Khan, M. I. R., Faroza Nazir, M., Asgher, T. S. \& Per, N. A. K. Selenium and sulfur influence ethylene formation and alleviate cadmium-induced oxidative stress by improving proline and glutathione production in whea. J. Plant Physiol. 173, 9-18 (2015).

7. Wu, Z. et al. Indications of selenium protection against cadmium and lead toxicity in oilseed rape (Brassica napus L.). Front. Plant Sci. 7, 1875 (2016).

8. Chen, J. et al. Epidemiological study of kidney health in an area with high levels of soil cadmium and selenium: Does selenium protect against cadmium-induced kidney injury?. Sci. Total Environ. 698, 134106 (2020).

9. Hu, Y., Norton, G. J., Duan, G., Huang, Y. \& Liu, Y. Effect of selenium fertilization on the accumulation of cadmium and lead in rice plants. Plant Soil 384, 131-140 (2014).

10. Zhang, Z., Gao, S. \& Shan, C. Effects of sodium selenite on the antioxidant capacity and the fruit yield and quality of strawberry under cadmium stress. Sci. Hortic. 260, 108876 (2020).

11. Wu, C., Dun, Y., Zhang, Z., Li, M. \& Wu, G. Foliar application of selenium and zinc to alleviate wheat (Triticum aestivum L.) cadmium toxicity and uptake from cadmium-contaminated soil. Ecotoxicol. Environ. Saf. 190, 110091 (2020).

12. Melesse, A., Steingass, H., Boguhn, J., Schollenberger, M. \& Rodehutscord, M. Effects of elevation and season on nutrient composition of leaves and green pods of Moringa stenopetala and Moringa oleifera. Agrofor. Syst. 86, 505-518 (2012).

13. Anwar, F., Latif, S., Ashraf, M. \& Gilani, A. H. Moringa oleifera: A food plant with Multiple Medicinal Uses. Phytotherapy Research. 21, 17-25 (2007).

14. Förster, N., Ulrichs, C., Schreiner, M., Müller, C. T. \& Mewis, I. Development of a reliable extraction and quantification method for glucosinolates in Moringa oleifera. Food Chem. 166, 456-464 (2015).

15. Tetteh, O. N. A. et al. Effects of harvest techniques and drying methods on the stability of glucosinolates in Moringa oleifera leaves during post-harvest. Sci. Hortic. 246, 998-1004 (2019).

16. Prabakaran, M., Kim, S. H., Sasireka, A., Chandrasekaran, M. \& Chung, I. M. Polyphenol composition and antimicrobial activity of various solvent extracts from different plant parts of Moringa oleifera. Food Biosci. 26, 23-29 (2018)

17. Ibrahim, R. E., El-Houseiny, W., Behairy, A., Mansour, M. F. \& Abd-Elhakim, Y. M. Ameliorative effects of Moringa oleifera seeds and leaves on chlorpyrifos-induced growth retardation, immune suppression, oxidative stress, and DNA damage in Oreochromis niloticus. Aquaculture 505, 225-234 (2019).

18. Cho, Y. W., Yun, J. H., Kwon, S. H., Eom, Y. J. \& Kim, W. J. Aggregate removal of particulate matter by selective protein-rich fraction of Moringa oleifera extract. J. Ind. Eng. Chem. 81, 161-166 (2020).

19. Nouhi, S., Kwaambwa, H. M., Gutfreund, P. \& Rennie, A. R. Comparative study of flocculation and adsorption behaviour of water treatment proteins from Moringa peregrina and Moringa oleifera seeds. Sci. Rep. 9, 1-9 (2019).

20. Amaglo, N. K. et al. Profiling selected phytochemicals and nutrients in different tissues of the multipurpose tree Moringa oleifera L., grown in Ghana. Food Chem. 122, 1047-1054 (2010).

21. Atawodi, S. E. et al. Evaluation of the polyphenol content and antioxidant properties of methanol extracts of the leaves, stem, and root barks of Moringa oleifera L.. J. Med. Food 13, 710-716 (2010).

22. Pachauri, S. D., Khandelwal, K., Singh, S. P., Sashidhara, K. V. \& Dwivedi, A. K. HPLC method for identification and quantification of two potential anti-inflammatory and analgesic agents-1,3-dibenzyl urea and aurantiamide acetate in the roots of Moringa oleifera. Med. Chem. Res. 22, 5284-5289 (2013).

23. Cui, C. et al. Characterization of Moringa oleifera roots polysaccharide MRP-1 with anti-inflammatory effect. Int. J. Biol. Macromol. 132, 844-851 (2019).

24. Channarong, M., Pimjai, C., Phawachaya, P., Saovaros, S. \& Siriporn, T. Moringa oleifera pod inhibits inflammatory mediator production by lipopolysaccharide-stimulated RAW 2647 murine macrophage cell lines. Inflammation 35, 445-455 (2012).

25. Kumar, P. \& Chauhan, M. S. Adsorption of chromium (VI) from the synthetic aqueous solution using chemically modified dried water hyacinth roots. J. Environ. Chem. Eng. 7, 110091 (2019).

26. Medas, D. et al. Impact of $\mathrm{Zn}$ excess on biomineralization processes in Juncus acutus grown in mine polluted sites. J. Hazard. Mater. 370, 98-107 (2019).

27. Szatanik-Kloc, A., Horn, R., Lipiec, J., Siczek, A. \& Boguta, P. Initial growth and root surface properties of dicotyledonous plants in structurally intact field soil and compacted headland soil. Soil Tillage Res. 195, 104387 (2019).

28. Mukrimin, M. et al. Fourier-transform infrared (FT-IR) spectroscopy analysis discriminates asymptomatic and symptomatic Norway spruce trees. Plant Sci. 289, 1-7 (2019).

29. Guo, X. et al. Hemicellulose modification promotes cadmium hyperaccumulation by decreasing its retention on roots in Sedum alfredii. Plant Soil 447, 241-255 (2020).

30. Weiler, F. H., dos Santos, G. F., Vescia, L. R., da Silva, R. A. \& Flôres, F. M. Simultaneous determination of sulfur, nitrogen and ash for vegetable tannins using ATR-FTIR spectroscopy and multivariate regression. Microchem. J. 149, 103994 (2019).

31. Sarabandi, K. et al. Production of reconstitutable nanoliposomes loaded with flaxseed protein hydrolysates: stability and characterization. Food Hydrocolloids 96, 442-450 (2019).

32. Barón, M. et al. The influence of irrigation solutions in the inorganic and organic radicular dentine composition. Aust. Endodod. J. 8, 1-9 (2020). 
33. Chen, H. et al. Qualitative and quantitative analysis of wood samples by Fourier transform infrared spectroscopy and multivariate analysis. Carbohydr. Polym. 82, 772-778 (2010).

34. Kumssa, D. B. et al. Challenges and opportunities for Moringagrowers in southern Ethiopia and Kenya. PLoSONE. 12, 1-15 (2017).

35. Lyons, G., Gondwe, C., Banuelos, G.,Mendoza, M. C. Z., Haug, A., Christophersen, O. A. Drumming up selenium and sulphur in Africa: Improving nutrition with Moringa Oleifera.ResearchGate. Preprint athttps://ajfand.net/Volume15/No1/REPRINT-GRAHA M\%20LYONS\%20on\%20SELENIUM\%20again.pdf (2013).

36. Schiavon, M. \& Pilon-Smits, E. A. H. Selenium biofortification and phytoremediation phytotechnologies: a review. J. Environ. Qual. 46, 10-19 (2017).

37. Ma, X., Su, Z. \& Ma, H. Molecular genetic analyses of abiotic stress responses during plant reproductive development. J. Exp. Bot. 10, 2870-2885 (2020).

38. Dai, Z. et al. Nitric oxide alleviates selenium toxicity in rice by regulating antioxidation, selenium uptake, speciation and gene expression. Environ. Pollut. 257, 113540 (2020).

39. Cui, J., Liu, T., Li, Y. \& Li, F. Selenium reduces cadmium uptake into rice suspension cells by regulating the expression of lignin synthesis and cadmium-related genes. Sci. Total Environ. 644, 602-610 (2018).

40. Anjum, S. A., Wang, L., Farooq, M., Khan, I. \& Xue, L. Methyl Jasmonate-Induced alteration in lipid peroxidation, antioxidative defence system and yield in soybean under drought. J. Agron. Crop Sci. 197, 296-301 (2011).

41. Wu, H. et al. Co-overexpression FIT with AtbHLH38 or AtbHLH39 in Arabidopsis-enhanced cadmium tolerance via increased cadmium sequestration in roots and improved iron homeostasis of shoots. Plant Physiol. 158, 790-800 (2012).

42. van de Mortel, J. E. et al. Expression differences for genes involved in lignin, glutathione and sulphate metabolism in response to cadmium in Arabidopsis thaliana and the related $\mathrm{Zn} / \mathrm{Cd}$-hyperaccumulator Thlaspi caerulescens. Plant Cell Environ. 31, 301-324 (2008).

43. Wang, J. et al. Transcriptome-wide comparison of selenium hyperaccumulator and nonaccumulator Stanleya species provides new insight into key processes mediating the hyperaccumulation syndrome. Plant Biotechnol. J. 16, 1582-1594 (2018).

44. Tinggiang, L. et al. Root cell wall polysaccharides are involved in cadmium hyperaccumulation in Sedum alfredii. Plant Soil 389, 387-399 (2015).

45. da Silva, D. F. et al. Anatomical and physiological characteristics of Raphanus sativus L. submitted to different selenium sources and forms application. Sci. Hortic. 260, 108839 (2020).

46. Zhao, Y. et al. Selenium reduces cadmium accumulation in seed by increasing cadmium retention in root of oilseed rape (Brassica napus L.). Environ. Exp. Bot. 158, 161-170 (2019).

\section{Acknowledgements}

This research was supported by the Yunnan Academy of Agricultural Sciences, China (YJM201701).

\section{Author contributions}

Z.F., G.L., and L.D. L.W. wrote the main manuscript text and H.Y., B.Y. prepared figures, Q.O. prepared Table 1. All authors reviewed the manuscript.

\section{Competing interests}

The authors declare no competing interests.

\section{Additional information}

Correspondence and requests for materials should be addressed to G.L. or L.D.

Reprints and permissions information is available at www.nature.com/reprints.

Publisher's note Springer Nature remains neutral with regard to jurisdictional claims in published maps and institutional affiliations.

(c) (i) Open Access This article is licensed under a Creative Commons Attribution 4.0 International (c) License, which permits use, sharing, adaptation, distribution and reproduction in any medium or format, as long as you give appropriate credit to the original author(s) and the source, provide a link to the Creative Commons licence, and indicate if changes were made. The images or other third party material in this article are included in the article's Creative Commons licence, unless indicated otherwise in a credit line to the material. If material is not included in the article's Creative Commons licence and your intended use is not permitted by statutory regulation or exceeds the permitted use, you will need to obtain permission directly from the copyright holder. To view a copy of this licence, visit http://creativecommons.org/licenses/by/4.0/.

(C) The Author(s) 2020 